\section{CEREBROSPINAL RHINORRHEA.}

\section{N. KINSHAN, M.D. COlumbus, OHIO.}

Mistory.-Mrs. H., aged 44, never seriously ill, was, in October, 1907 , subsequent to an attack of infuenza, forcibly clearing the posterior nares by inspiration through the nose when she detached a seab of the size and appearance of a vaccine crust. Immediately there was a profuse discharge of a saltish fluid from the right nostril; this has been continuous ever since. She visited me at my office Jan. 5, 1908.

Examination.-She was a large woman, fat, and of good color. Her forchead, cheels and chin were covered with a shield-shaped eruption (eczema rubrum) due to constant use of handkerchiefs to keep the discharge from soiling her clothing. She could divert the discharge either to the nostril or pharynx at will, by inclining the head forward or backward, She had been treated by plugging the nose and the use of argonin, arsenic and sodium bromid and belladonna. The chronicity and quantity of the discharge, which escaped at the rate of three drops a minute, convinced me I was not dealing with an ordinary rhinitis.

Exomination of Fluid.-The fluid was transparent and in it wrre two flakes of mucus, floating. On standing, there was a depesit of epithelial cells from the nares. No cells from the cerebrospinal cavity were seen. The fluid was alkaline, with a faint reaction for sodium chlorid. The application of heat and nitric acid gave no deposit. On cooling, a faint white cloud appeared, showing the presence of albumose, and it reacted with a reddish-orange deposit to Fehling's test.

According to Simon, the above reactions in a discharge coming from the nostrils indicate that it is cerebrospinal fluid. Traumatisms of the skull, spinal punctures and cerebral tumors causing a breach of the membranes enveloping the brain have made us familiar with the chemistry of this fluid.

A letter, dated February 24, says that the discharge continues. A careful examination when $I$ last saw her failed to show any visual or muscular defects of the eye. There were no cerebral disturbances and the refiexes were normal.

Sidney I. Schwab and John Green; Jr., report one case with a summary of twenty cases of cerebrospinal rhinorrhea reported by Dr. St. Clair Thompson, ${ }^{2}$ all the known reported cases at that time (1899). From this paper we learn that about 75 per cent. of the patients suffer from risual defects, such as optic neuritis, optic atrophy and hemiopia. The diagnosis in such cases rests on the analysis of the fluid. The prognosis as to recovery is unlavorable, though the danger from infection does not scem to be great. Patients have lived from five to ten years. There is no treatment which promises relief.

\section{A CASE OF TIXCENT'S ANGINA WITHOUT SPIROCHETES.}

COMMENTS ON TIE LSE OF DIRECT SMEARS IN DIAGNOSING ACUTE EXUDATIVE AFFECTIONS OF THE THROAT.

WALTER H. BUHLIG, B.S., M.D.

Instructor in Clinical Pathology, Northwestern University Medical School.

CIIICAGo.

It is the belief among many physicians that acute diseases of the throat with exudate can be promptly and conclusively diagnosed from the direct smear alone, thus saving whatever time would elapse before the culture is ready for examination. Because of this I am often pressed for a decision from a direct smear, al.

1. Am. Invr Mad. Scl. May, 1905

2. Brit. Med. Jour., 1899. tlough I have certain firm convictions concerning the value of such examinations.

It has been my experience that when direct smears from an exudate show only cocci and the tendency, therefore would be to diagnose an absence of diphtheria, cultures on Locffler serum may produce characteristic diphtheria bacilli. On the other hand, there are, from other exudates, microscopic pictures in which there are bacilli so much like diphtheria organisms that a positive diagnosis of Klebs-Loeffler infection would be made and the culture disprove this conclusion. I have, therefore, been rather dogmatic to students in this relation and insist that the absence of diphtheria can never be cecided by direct smear alone, and that in isolated instances the presence of diphtheria may be reported, if there is the proper evidence. This evidence, it is taught, consists of predominance of bacilli of the size and morphology of the Klebs-Loeffler bacillus, without insisting on the presence of granules in the bacilli. Such more deeply staining structures in the bacillus assist in the diagnosis and are always to be searched for, but their absence need not necessarily negative the diagnosis. Caution, in any case, is rigidly taught, and cultural methods are always to be used for control.

With this rather trite introduction, the case to be reported is of interest. The patient had an exudate and an immediate diagnosis was requested. Nineteen direct smcars were examined by as many members of a section in clinical pathology, and controlled by me. In practically every specimen there was an overwhelming predominance of slender, somewhat pointed bacilli of about the length and thickness of the Klebs-Loeffier organism. Diphtheria was diagnosed. Special note was made of the pointed cxtremities and the possibility of Vincent's angina was considered in the discussion of the smears, but the absence of spirochetes, except one found by the instructor in all the specimens, was bélieved for pract:cal purposes to rule out that affection, although the occurrence of only the fusiform bacilli in that disease was mentioned. Knowing of the presence of spirochetes in the mouth, this single one was at the time adjudged one of that kind. The culture was absolutely negative, even after 48 hours.

So this case is adjudged Vincent's angina without spirochetes from the absence of diphtheria and other organisms in the culture, from the abundance of fusiform bacilli in the smears, and from the inability to grow them under aërobic conditions.

\section{ADHESION OF APPENDIX TO UTERUS.}

\section{T. QUIGLEY, M.D. \\ NORTH PLATTE, NEB.}

History.-The patient was a woman, 20 years of age, wife of a physician, formerly a trained nurse, family history good, and no ill health previously, except that about a year before my seeing her, during her hospital work, she had had an attack which had been diagnosed as appendicitis. This passed off in a few days and she had no more trouble, except occasional soreness in the abdomen.

At the time I saw her she had fever of two or three degrees. She had been vomiting almost incessantly for three weeks, but what gave her the most trouble was a very severe pain in the lower abdomen. The pain was continuous, and at times took on a cramping character which made it excrutiating. She had been having increasing doses of morphin, hypodermically, for three weeks, and as the morphin was becoming a menace to her life, and her condition was becoming steadily worse, I advised an operation as soon as preparations could be made. 